\title{
Differential Effects of Voluntary Ethanol Consumption on Dopamine Output in the Nucleus Accumbens Shell of Roman High- and Low-Avoidance Rats: A Behavioral and Brain Microdialysis Study
}

\author{
Maria G. Corda, Giovanna Piras*, Maria A. Piludu, Osvaldo Giorgi\# \\ Department of Life and Environmental Sciences, Section of Pharmacological, Pharmaceutical and \\ Nutraceutical Sciences, University of Cagliari, Cagliari, Italy \\ Email: "giorgi@unica.it
}

Received 4 May 2014; revised 1 June 2014; accepted 18 June 2014

Copyright (C) 2014 by authors and Scientific Research Publishing Inc. This work is licensed under the Creative Commons Attribution International License (CC BY). http://creativecommons.org/licenses/by/4.0/

(c) (i) Open Access

\section{Abstract}

The Roman high- (RHA) and low-Avoidance (RLA) rats were selectively bred for rapid vs poor acquisition of two-way active avoidance behavior. These lines differ in numerous behavioral traits, with RLA rats being more fearful/anxious than RHA rats, and the latter being novelty-seekers and showing larger intake of, and preference for, addictive substances including ethanol (ETH). Moreover, several differences in central dopaminergic, serotonergic, and GABAergic functions have been reported in these two lines. Since those neural systems are involved in the regulation of ETH consumption, it was considered of interest to investigate: 1) the differences in ETH intake and preference between RHA and RLA rats, 2) the effects of ETH on DA release in the shell of the nucleus accumbens (AcbSh) using brain microdialysis. ETH solutions of increasing concentrations (2\% - 10\%) were presented on alternate days in a free choice with water. To examine ETH intake and preference stability, animals were subsequently switched to daily presentations of $10 \%$ ETH for 10 consecutive days. RHA rats consumed significantly larger amounts of ETH and displayed higher ETH preference than did RLA rats throughout the acquisition and maintenance phases. Following chronic exposure to ETH the animals were habituated to a restricted access to ETH schedule $(2 \%$ ETH, $2 \mathrm{~h}$ per day $\times 4$ days) before surgical implantation of a dialysis probe in the AcbSh. Under these experimental conditions, voluntary ETH intake $(2 \%, 1 \mathrm{~h}$, p.o.) produced a significant increase in accumbal DA output in RHA rats but not in their RLA counterparts. Finally, the i.p. administration of ETH $(0.25 \mathrm{~g} / \mathrm{kg})$ to naïve Roman rats produced a significant increment in accumbal DA output only

\footnotetext{
*Present address: Department of Biomedical Sciences, Section of Neuropsychopharmacology, University of Cagliari, Italy.

\#Corresponding author.
} 
in RHA rats. These results indicate that the mesolimbic dopaminergic system of RHA rats is more responsive to the effects of ETH than that of RLA rats.

\title{
Keywords
}

\author{
Roman High- and Low-Avoidance Rats, Voluntary Ethanol Consumption, Mesolimbic Dopaminergic \\ System, Nucleus Accumbens Shell, Novelty-Seeking Behavior
}

\section{Introduction}

Although non selected outbred Wistar rats and heterogeneous stock rats (e.g., N/Nih) drink relatively small amounts of ethanol (ETH) voluntarily, considerable inter individual differences in the amounts of ETH consumed by these rats have been observed [1] [2]. Taking advantage of such differences, some of which may be genetically determined, efforts have been made to develop animal models for studying the influence of genetic and environmental factors on the neural substrates of alcoholism. In this context, a frequently employed strategy is based on the selective breeding of rodent strains and lines, such as the Alcohol preferring (P) [3], Alcoholaccepting (Alko Alcohol-AA) [4], and Sardinian alcohol-preferring (sP) rats [5] that voluntarily consume up to 10 times more ETH as do non selected outbred rats. On the other hand, high alcohol drinking has also been observed in rats selectively bred for traits that are unrelated to any of the major traits of alcoholism [6] [7]. The Roman high-(RHA) and low-avoidance (RLA) rats, which were selected and bred for respectively rapid vs poor acquisition of two-way active avoidance behavior in a shuttle box [8] [9], are an example of fortuitous selection for differential ETH consumption. Thus, there is considerable evidence that RHA rats drink significantly more ETH than RLA rats [10]-[12]. Numerous studies have consistently demonstrated that behavioral traits related to emotionality/fearfulness, rather than learning abilities, are involved in the different performance of the Roman lines in the shuttle-box. Thus, in behavioral paradigms used to assess emotionality/fearfulness in rodents, RHA rats are less responsive to stress than RLA rats, show a proactive coping style and tend to be impulsive and sensation/novelty seekers [13]-[18]; in contrast, RLA rats adopt a reactive coping style [19]-[24] and display a robust activation of the hypothalamus-pituitary-adrenal (HPA) axis [25]-[27]. Line-related differences are also observed in the response to rewarding stimuli, with RHA rats showing a greater intake of saccharin and ethanol under free choice conditions [10], a more robust activation of the mesolimbic dopaminergic system following the administration of different drugs of abuse [28] [29], as well as an increased ability to acquire intravenous cocaine self-administration and to reinstate drug-seeking behavior upon long term extinction [30].

Two alternative hypotheses may be proposed to explain why the above mentioned wide variety of selected rat lines/strains [1] [4] [5] [10] voluntarily consume large amounts of ETH: 1) ETH-preferring rats drink large amounts of ETH because they are innately anxious and the consumed ETH acts as an anxiolytic, and 2) they consume ETH because of a dysfunctional brain reward system such that they lose control of the intake of ETH and other addictive substances as well. Interestingly, there is experimental evidence in support of both hypotheses. For instance, it has been reported that sP rats are innately anxious and drink ETH because of its anxiolytic effect [31] [32]. On the other hand, it is well known that most addictive substances, including ETH, share the ability to increase DA output in the nucleus accumbens (Acb) [33]-[35], and this effect is more robust in the medioventral shell subregion of this nucleus (AcbSh) than in the dorsolateral core (AcbC) [36]. In line with the second hypothesis, the intraperitoneal (i.p.) administration of ETH induces a more robust increase of DA output in the AcbSh of ETH-preferring University of Chile bibulous (UChB) than ETH-avoiding University of Chile Abstainer (UChA) rats [37].

On the bases of the experimental evidence described above, we predicted that the consumption of large amounts of ETH by RHA rats would induce a more robust activation of the mesolimbic dopaminergic projections in this line as compared with their RLA counterparts, who drink very little ETH voluntarily despite their high level of anxiety. To test this hypothesis we used brain microdialysis to measure the effect of the voluntary consumption of ETH or water on DA output in the AcbSh of RHA and RLA rats upon chronic exposure to ETH in a free choice with water. In addition, we investigated the effect of the intraperitoneal (i.p.) injection of ETH at the dose of $0.25 \mathrm{~g} / \mathrm{kg}$ on the accumbal efflux of DA in both lines. 


\section{Materials and Methods}

\subsection{Animals}

Outbred RHA and RLA rats (body weight 460 - 520 g) from the colony established in 1998 at the University of Cagliari, Italy, were used throughout (for a detailed description of the selective breeding procedure, see [38]). Animals were housed in groups of 4 per cage and were maintained in a temperature- and humidity-controlled environment $\left(23^{\circ} \mathrm{C} \pm 11^{\circ} \mathrm{C}\right.$ and $60 \% \pm 10 \%$, respectively) and under a $12 \mathrm{~h}$ light-dark cycle (lights on at 8:00 a.m.). Unless otherwise indicated, standard laboratory food (Mucedola, Milan, Italy) and water were available ad libitum.

All the procedures were performed in accordance with the guidelines and protocols approved by the European Union (2010/63/EU; D.L. 27.01. 1992, NO.116) and by the Ethical Committee for Animal Care and Use of the University of Cagliari. Every possible effort was made to minimize animal pain and discomfort as well as the number of experimental subjects used.

\subsection{Ethanol Consumption Studies}

Sixteen RHA and sixteen RLA rats were individually housed in Plexiglass cages $(42 \mathrm{~cm} \times 27 \mathrm{~cm} \times 15 \mathrm{~cm}, \mathrm{~L} \times$ $\mathrm{W} \times \mathrm{H}$ ) equipped with a wire lid. Throughout the experiments, animals had continuous access to either water or ETH contained in two graduated plastic bottles (100 ml capacity) mounted on the front of the cages. Each bottle had a metallic sipper tube equipped with a ball to minimize spillage. Following a 5-day habituation period in which both bottles contained tap water, animals entered the acquisition phase in which, on alternate days, they had access to ETH solutions of increasing concentrations in $24 \mathrm{~h}$ cycles and in a free choice with water. The different concentrations of ETH used during the acquisition phase were freshly prepared every day by diluting in tap water a stock solution of 96\% ETH (Silvio Carta, Cagliari, Italy). The initial ETH concentration was 2\% (v/v), and 1\% increments were applied every second day until a final ETH concentration of $10 \%$ was achieved by day 17. Both bottles contained tap water in the intervening days. The animals were then switched to the maintenance phase in which they had continuous access to $10 \%$ ETH in a free choice with water for 10 consecutive days. ETH and water consumption was measured by weighing the bottles before and after each $24 \mathrm{~h}$ cycle (between 10 a.m. and 12.00 a.m.). Animals were weighed on alternate days in order to calculate ETH intake as g of absolute ETH/kg body weight, and ETH preference was calculated as follows:

$$
\text { ETH preference }=[\text { ETH intake }(\mathrm{ml}) /(\mathrm{ETH} \text { intake }(\mathrm{ml})+\text { water intake }(\mathrm{ml}))] \times 100
$$

\subsection{Restricted Access to Fluids Schedule}

Upon completion of the maintenance phase, animals were switched to the restricted access to fluids schedule, in which they had free access to $2 \%$ ETH or water for $2 \mathrm{~h}$ (10.00 a.m. to 12.00 a.m.) in each of the four days that preceded the implantation of the dialysis probe. No other fluids were available during this 4-day period. During the brain dialysis experiments that were performed $24 \mathrm{~h}$ after probe implantation, the rats that had been exposed to $2 \%$ ETH during the restricted access to fluids phase were presented with the same concentration of ETH for 1 $\mathrm{h}$, whereas the rats that had been exposed to water were presented with water, also for $1 \mathrm{~h}$.

\subsection{Acute Ethanol Administration}

RHA and RLA rats never exposed to ETH were implanted with dialysis probes aimed at the AcbSh as described in the next paragraph and $\cong 24 \mathrm{~h}$ later, during the brain dialysis assays, were injected intraperitoneally (i.p.) with ETH at the dose of $0.25 \mathrm{~g} / \mathrm{kg} / 2 \mathrm{ml}$.

\subsection{Surgery}

Rats were anaesthetized with chloral hydrate $(450 \mathrm{mg} / \mathrm{kg}$, i.p.) and then immobilised in a stereotaxic apparatus (David Kopf Instruments, USA). The vertical dialysis probes with a concentric design were made as previously described [38] and unilaterally implanted in the AcbSh, using the following stereotaxic coordinates (according to [39]): A, $+2.0 \mathrm{~mm}$; $\mathrm{L}, \pm 0.9 \mathrm{~mm}$ from bregma and V, $-7.8 \mathrm{~mm}$ from dura. Animals were then placed in hemispheric Perspex bowls $(\varnothing=60 \mathrm{~cm})$ located in a sound-attenuated room, and left there until completion of the brain dialysis experiments. 


\subsection{Brain Microdialysis and Chromatographic Assays}

Brain dialysis experiments were started $\cong 20$ - $24 \mathrm{~h}$ after surgery on freely moving rats. The DA content in the brain dialysates was determined on line using the procedure described by Giorgi et al. [38]. Briefly, Ringer's solution $\left(147 \mathrm{mM} \mathrm{NaCl}, 4 \mathrm{mM} \mathrm{KCl}\right.$ and $2.2 \mathrm{mM} \mathrm{CaCl}_{2}$ ) was pumped through the inlet of the dialysis probe at a constant rate of $1.0 \mu \mathrm{l} / \mathrm{min}$. Dialysate samples were collected at $20 \mathrm{~min}$ intervals for $2-3 \mathrm{~h}$ before presenting the bottle containing the $2 \%$ ETH solution or tap water, or before the administration of ETH i.p. and for $3 \mathrm{~h}$ thereafter. Immediately after collection, dialysates (20 $\mu \mathrm{l})$ were injected without purification in an HPLC system equipped with a reverse phase chromatographic column (Supelco, LC-18 DB, $150 \mathrm{~mm} \times 4.5 \mathrm{~mm}, 5 \mu \mathrm{m}$ particle size) and an electrochemical detector (Antec, model CU 04A2) whose working electrode was set at $+500 \mathrm{mV}$ vs. the reference electrode. The mobile phase $\left(100 \mathrm{mM} \mathrm{NaH} \mathrm{PO}_{4} / \mathrm{Na}_{2} \mathrm{HPO}_{4}, 0.1 \mathrm{mM} \mathrm{Na}\right.$-EDTA, $0.48 \mathrm{mM}$ n-octyl-Nasulphate, $15 \% \mathrm{v} / \mathrm{v}$ methanol, $\mathrm{pH}$ 5.5) was pumped at a rate of $1.2 \mathrm{ml} / \mathrm{min}$ using an HPLC pump (Kontron, model 422). The sensitivity of the DA assay was $3 \mathrm{fmol}$ (signal to noise ratio $\sim 3$ ).

\subsection{Data Presentation and Statistical Analysis}

1) Behavioural measures. All fluid intake and body weight data were evaluated by two-way ANOVA with animal line (i.e., RHA vs RLA) and time (i.e., day number) as main factors, with repeated measures over time. When appropriate (i.e. $\mathrm{p}<0.05$ for the main factors and/or their interactions), post hoc pairwise comparisons were made with the LSD Fisher's test.

2) Brain microdialysis. For each experiment, dialysate samples were collected and assayed on line to ensure that the baseline DA content was stable before starting the experiment. The stability criterion was a variation $<10 \%$ in at least three consecutive baseline samples, and was usually met after $2-3 \mathrm{~h}$. The baseline DA output was then calculated as the mean of 3 consecutive samples preceding the administration of ETH or water. The mean baseline DA output values of RHA and RLA rats, expressed as fmol/20 $\mu$ dialysate, were compared by one-way ANOVA, whereas the effects of water or ETH consumption on accumbal DA output were expressed as percent of the respective mean baseline values and were analysed by multifactor ANOVA with fluid (water vs ETH) and line (RHA vs RLA) as the main factors and with repeated measures over time. Finally, for the analysis of data shown in Figure 4 the main factor was line, with repeated measures over time after i.p. ETH injection $(0.25 \mathrm{~g} / \mathrm{kg} / 2 \mathrm{ml})$. Multiple pair wise contrasts were made with the LSD Fisher's test. The significance level for all the statistical tests was set at $\mathrm{p}<0.05$.

\subsection{Histology}

At the end of the brain microdialysis experiments, rats were anaesthetized with chloral hydrate $(450 \mathrm{mg} / \mathrm{kg}$, i.p.) and perfused transcardially with $50 \mathrm{ml}$ of physiological saline, followed by $100 \mathrm{ml}$ of $10 \%$ formalin. Brains were immediately removed from the skull and stored at room temperature in $10 \%$ formalin for at least two days. Serial coronal brain sections ( $100 \mu \mathrm{m}$ thick) were then cut with a vibratome, and the location of each probe was verified using the atlas of Paxinos and Watson [39] as a reference.

\section{Results}

\subsection{Ethanol and Total Fluid Consumption during the Acquisition Phase and the Maintenance Phase}

RHA rats consumed significantly more ETH than RLA rats throughout the acquisition phase (Figure 1(a)), as indicated by two-way ANOVA (line, $\mathrm{F}(1,26)=28.49$, $\mathrm{p}<0.01$; ETH concentration, $\mathrm{F}(8,208)=17.13$, $\mathrm{p}<$ 0.01). Thus, in RHA rats, the ETH intake increased gradually with increasing ETH concentrations from $2 \%$ up to $7 \%$, remained stable with $8 \%$ and $9 \%$ ETH solutions, and tended to decrease slightly with $10 \%$ ETH. On the other hand, in RLA rats the increment in ETH intake was less pronounced, as indicated by a significant line X ETH concentration interaction $(F(8,208)=5.31, \mathrm{p}<0.01)$.

Figure 1(b) shows that both lines preferred $2 \%$ and 3\% ETH solutions over water, as indicated by the 95\% confidence intervals (C.I.: $50 \%<$ C.I. $<85 \%$ ). Moreover, RHA rats significantly preferred ETH over water up to a $7 \%$ concentration $(51 \%<$ C.I. $<85 \%)$, whereas at higher concentrations $(8 \%$ to $10 \%)$ no preference for ETH or water was observed $(40 \%<$ C.I. $<61 \%)$. Conversely, ETH preference of RLA rats rapidly declined with 


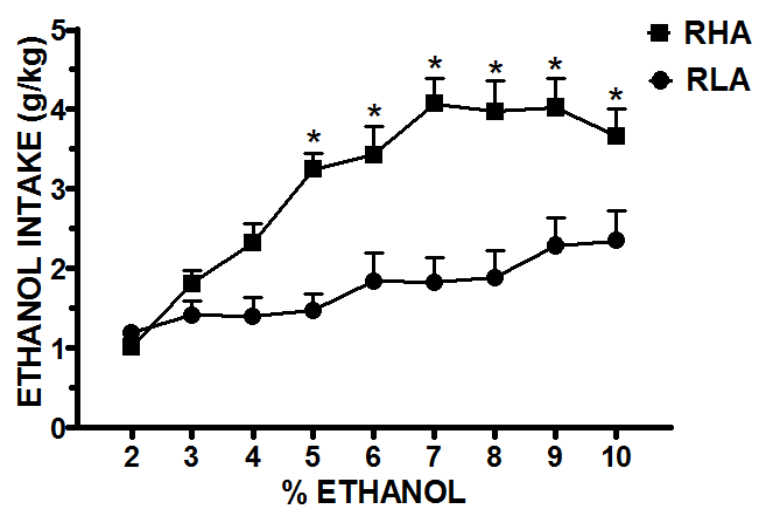

(a)

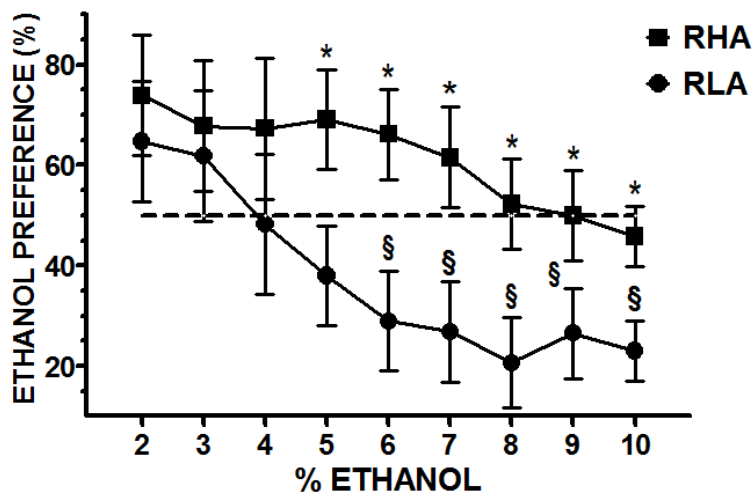

(b)

Figure 1. Ethanol consumption during the acquisition phase. (a) Intake: Results are expressed as the mean \pm S.E.M. daily ethanol (ETH) intake $(\mathrm{g} / \mathrm{kg})$ for concentrations ranging from $2 \%$ to $10 \%$ (day 1 to day 17 of the acquisition phase); (b) Preference: Shown are the mean and 95\% confidence interval for daily ETH preference (\%) for concentrations ranging from $2 \%$ to $10 \%$. The dotted horizontal line indicates $50 \%$ preference. $\mathrm{N}=14$ rats in each experimental group. ${ }^{*} \mathrm{p}<0.05$ vs the ETH concentrationmatched RLA value; ${ }^{\S} \mathrm{p}<0.05$ vs the line-matched $2 \%$ ETH value.

escalating ETH concentrations, so that water was preferred over ETH at concentrations $\geq 5 \%$ (11\% < C.I. < $48 \%)$.

As shown in Figure 2(a), ETH intake was significantly higher in RHA than RLA rats throughout the maintenance phase (line, $\mathrm{F}(1,26)=26.82, \mathrm{p}<0.01$; ETH concentration, $\mathrm{F}(9,234)=2.63$, $\mathrm{p}<0.01$ ); thus, the respective mean daily intake values for RHA and RLA rats were 3.40 and $1.49 \mathrm{~g} / \mathrm{kg}$. RHA rats did not show preference for ETH or water on days 1 to $6(31 \%<$ C.I. $<56 \%)$, but preferred water over ETH on the last four days of the maintenance phase $(25 \%<$ C.I. $<47 \%)$; in contrast, RLA rats preferred water over ETH throughout the maintenance phase $(7 \%<$ C.I. $<31 \%)$ (Figure 2(b)).

Total fluid consumption averaged across the acquisition phase and the maintenance phase tended to be lower in RHA (46.6 ml) than RLA rats $(55.4 \mathrm{ml})$; however, a line X day two way ANOVA revealed no significant effect of line, $F(1,26)=2.98, p=0.09$, day, $F(3,78)=0.17, p>0.05$, or their interaction, $F(3,78)=1.57, p>$ 0.05 .

\subsection{Body Weight}

Average weights for the entire experiment were $486 \pm 2$ and $508 \mathrm{~g} \pm 3 \mathrm{~g}$ for RHA and RLA rats, respectively. A 


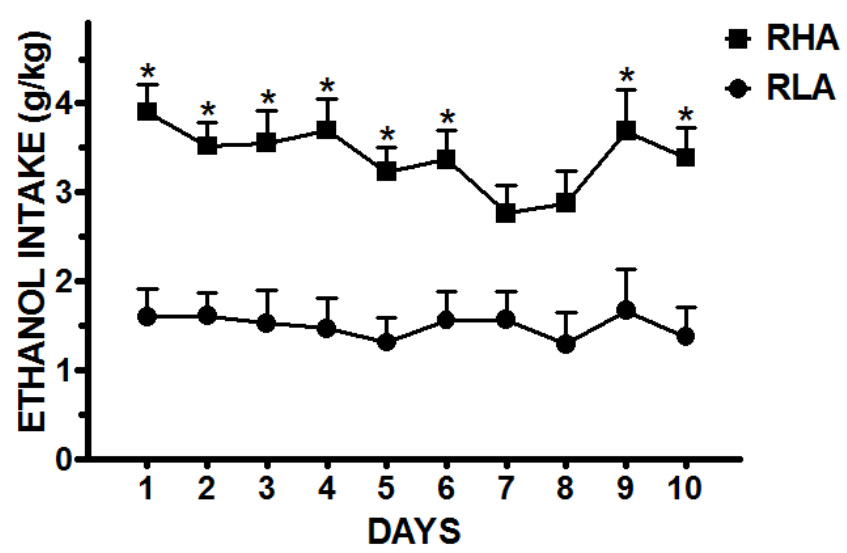

(a)

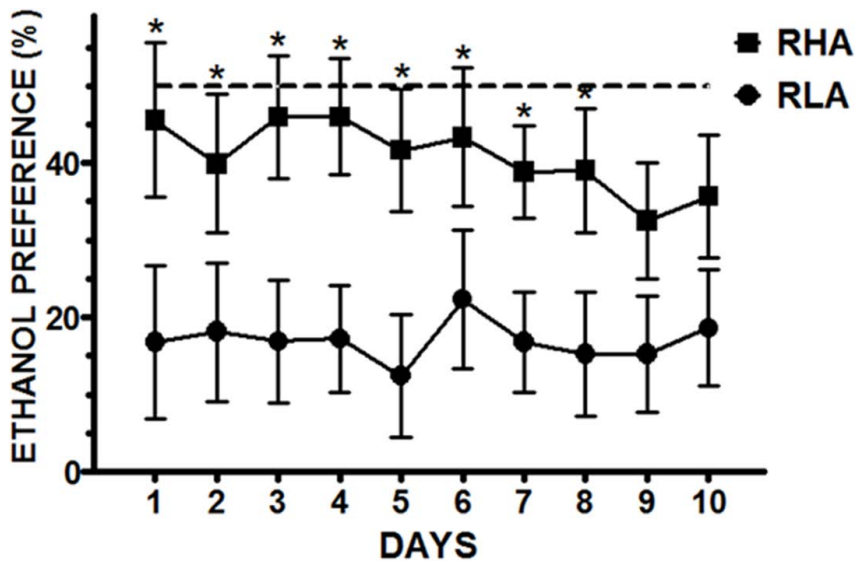

(b)

Figure 2. Ethanol consumption during the maintenance phase. (a) Intake: Results are expressed as the mean \pm S.E.M. ETH intake (g/kg) in days 1 to 10 of the maintenance phase; (b) Preference: Shown are the mean and 95\% confidence interval for ETH preference in days 1 to 10 of the maintenance phase. The dotted horizontal line indicates $50 \%$ preference. $\mathrm{N}=14$ rats in each experimental group. ${ }^{*} \mathrm{p}<0.05$ vs the day-matched RLA value.

two-way ANOVA yielded no significant effect of line, $\mathrm{F}(1,26)=1.12$, day, $\mathrm{F}(3,78)=0.26$, or their interaction, $\mathrm{F}(3,78)=0.002$, all $\mathrm{p}$ values $>0.05$.

\subsection{Ethanol Consumption and Accumbal Dopamine Output during Brain Dialysis}

As already mentioned, during the brain dialysis experiments the rats that had been exposed to $2 \%$ ETH during the restricted access to fluids phase were presented with the same concentration of ETH for $1 \mathrm{~h}$, whereas the rats that had been exposed to water were presented with water, also for $1 \mathrm{~h}$. ETH intake was significantly larger in RHA vs. RLA rats (line, $\mathrm{F}(1,16)=24.60, \mathrm{p}<0.01$ ) as was the total volume of $2 \% \mathrm{ETH}$ solution consumed (line, $\mathrm{F}(1,16)=19.50, \mathrm{p}<0.01)$ (Figure 3(a)).

The basal DA output (fmol/20 $\mu \mathrm{l}$ ) was similar in the four experimental groups: RHA water, $84 \pm 4.8$; RHA ETH, $77 \pm 9.6$; RLA water, $89 \pm 9.2$; RLA ETH, $79 \pm 6.2$; F(3, 24) $=0.34, p>0.05$. As shown in Figure 3(b), ETH consumption was associated with a small, albeit significant increase in DA output in RHA, but not in RLA rats; moreover, no significant changes in DA output were observed in association with water consumption in either line. Thus, a line $X$ fluid $X$ time analysis revealed a significant 3-way interaction $(F(10,240)=3.21, p<$ 0.01). Moreover, post hoc pairwise contrasts with the LSD Fisher's test revealed a significant increase in DA output vs the respective basal value in RHA rats between 20 and 100 min after the start of ETH presentation, 


\title{
- RHA 口 RLA
}

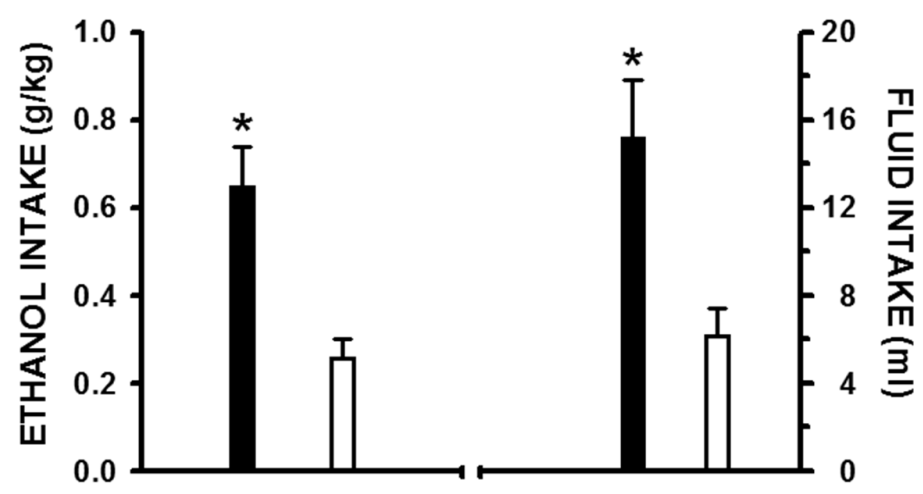

(a)

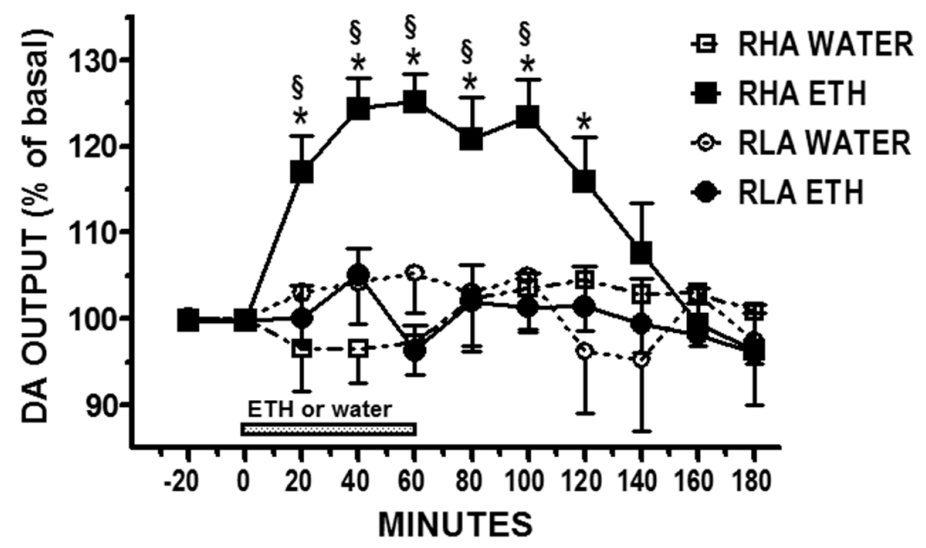

(b)

\begin{abstract}
Figure 3. Ethanol consumption during brain microdialysis and dopamine output in the AcbSh (a) Ethanol intake: Columns and bars indicate the mean \pm S.E.M. ETH intake (g/kg, left side) and total fluid intake (ml, right side) of RHA and RLA rats presented with a $2 \%$ ETH solution for 1 h. ${ }^{*} \mathrm{p}<0.05$ vs the RLA group; (b) Dopamine output in the AcbSh: Results are expressed as percent of the respective basal value. Shown are the mean \pm S.E.M. values obtained from rats presented, during the brain dialysis assay, with either water (RHA, $\mathrm{N}=6$; RLA, $\mathrm{N}=4$ ) or a $2 \%$ ethanol solution (RHA, $\mathrm{N}=8$; RLA, $\mathrm{N}=10$ ), for 1 h. ${ }^{*} \mathrm{p}<0.05$ vs the time-matched RLA-ethanol group and the RHA-water group; ${ }^{\S} \mathrm{p}<0.05$ vs the respective basal value.
\end{abstract}

with a peak value of $+25 \%$ over the baseline value at $60 \mathrm{~min}$.

\subsection{Effect of Ethanol Administration ( $0.25 \mathrm{~g} / \mathrm{kg}$, i.p.) on Accumbal Dopamine Output}

In order to clarify whether the lack of effect of voluntary oral ETH consumption on accumbal DA output in RLA rats was due to the lower ETH intake relative to that of their RHA counterparts, we investigated the effect of the non contingent i.p. administration of ETH at a dose of $0.25 \mathrm{~g} / \mathrm{kg}$, which is similar to the amount of ETH voluntarily consumed by RLA rats during the previous brain dialysis experiments. No line related differences were observed in the basal DA output (fmol/20 $\mu \mathrm{l}$ ): RHA, $87 \pm 9.8$; RLA, $80 \pm 7.3 ; \mathrm{F}(1,11)=0.32$, p > 0.05. On the other hand, as shown in Figure 4, the i.p. administration of ETH increased accumbal DA output only in RHA rats (line, $\mathrm{F}(1,11)=26.11, \mathrm{p}<0.01$; time, $\mathrm{F}(10,110)=6.85, \mathrm{p}<0.01$; line $\mathrm{X}$ time, $\mathrm{F}(10,110)=7.05$, $\mathrm{p}<$ 0.01); moreover, post hoc pairwise contrasts indicated that DA output in RHA rats was significantly higher than the respective baseline value between 20 and 140 min after ETH injection, with a peak value of $45 \%$ over the baseline value at $100 \mathrm{~min}$. 


\subsection{Histology}

Figure 5 shows the placement of the dialyzing portion of the probes in the AcbSh [39]. Only the data from 41 completed experiments corresponding to dialysis probes with active portions placed in the shaded areas shown in the diagrams of the figure were used for statistical evaluations. Neurochemical and behavioral data from 3 RHA rats (2 in the chronic ETH consumption experiment and 1 in the acute i.p. ETH experiment) and 4 RLA

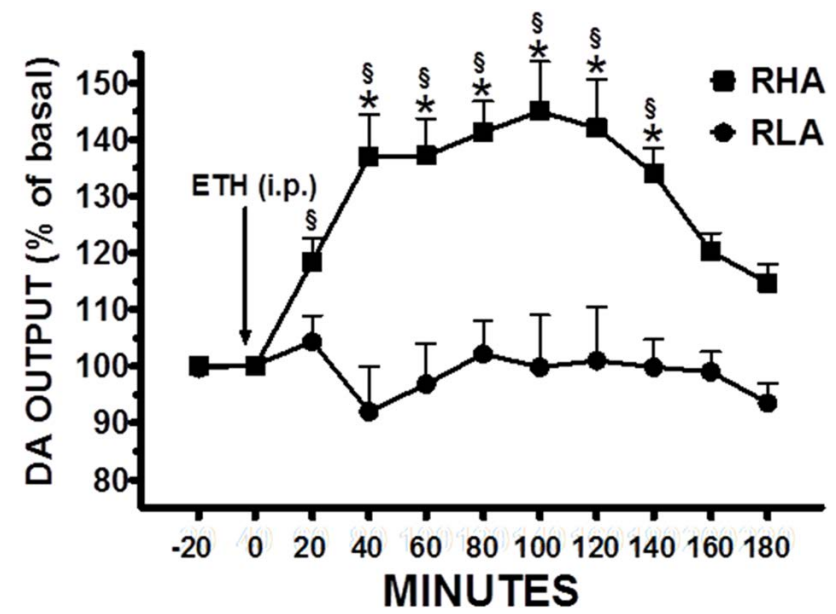

Figure 4. Effect of i.p. ethanol on dopamine output in the AcbSh. Dialysates were collected at 20 min intervals for $2 \mathrm{~h}$ before ethanol administration $(0.25 \mathrm{~g} / \mathrm{kg}$, i.p., arrow) and $3 \mathrm{~h}$ thereafter. Results are expressed as percent of the respective basal value. Shown are the mean \pm S.E.M. values obtained from 7 RHA and 6 RLA rats. ${ }^{*} \mathrm{p}<0.05$ vs the time-matched RLA group; ${ }^{\S} \mathrm{p}<0.05$ vs the respective basal value.

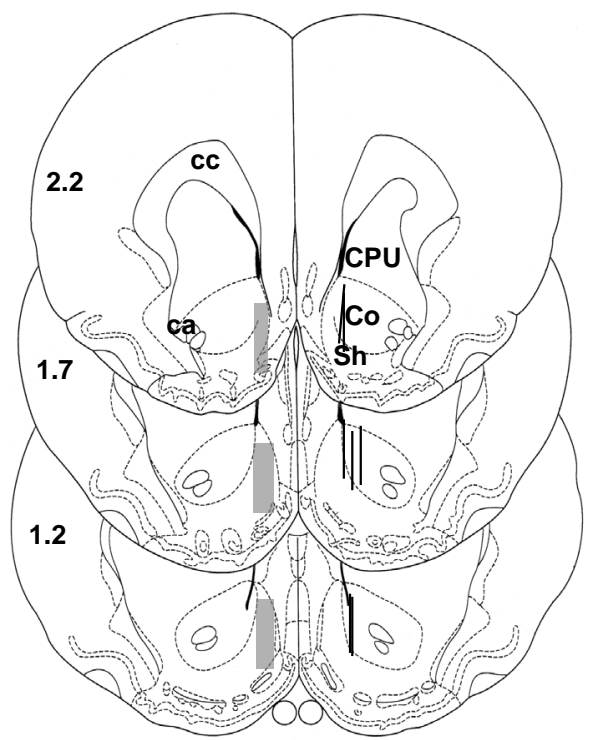

Figure 5. Atlas diagram showing the brain areas implanted with vertical microdialysis probes. For the clarity of presentation, the position of the active portion of the probes is schematically indicated by the grey bars drawn in the left hemisphere and the position of the misplaced probes is shown in the right hemisphere. The A-P coordinates according to Paxinos and Watson [39] are shown on the left side of each coronal section. Abbreviations: Co, nucleus accumbens core; Sh, nucleus accumbens shell; ca, anterior commissure; cc, corpus callosum; $\mathrm{Cl}$, claustrum; CPU, nucleus caudatusputamen. 
rats (2 in the chronic ETH consumption experiment and 2 in the acute i.p. ETH experiment) with misplaced probes were excluded from statistical analyses.

\section{Discussion}

The findings of the present study may be summarized as follows: 1) RHA rats drink more ETH than RLA rats in both, the acquisition phase and the maintenance phase of the two bottle ETH/water free choice paradigm, in keeping with previous reports using outbred and inbred Roman rats from different colonies, 2) during the brain dialysis experiment, voluntary ETH consumption is associated with a significant increase in DA output in the AcbSh of RHA but not RLA rats, and 3) the i.p. administration of ETH at the dose of $0.25 \mathrm{~g} / \mathrm{kg}$ induces a significant increment in DA output in the AcbSh in RHA rats but not in their RLA counterparts.

ETH intake and preference were larger in RHA vs. RLA rats throughout the acquisition phase. No significant difference in ETH intake was observed between the Roman lines at low concentrations (i.e., 2\% and 3\%); however, in RHA rats, a rapid increment in ETH intake from $\sim 1 \mathrm{~g} / \mathrm{kg}$ up to $\sim 4 \mathrm{~g} / \mathrm{kg}$ was observed with increasing ETH concentrations from $2 \%$ to $7 \%$ - 9\%, followed by a slight decrease with $10 \% \mathrm{ETH}$, whereas the increment in ETH intake with increasing concentrations was much less pronounced in RLA rats (from $\sim 1 \mathrm{~g} / \mathrm{kg}$ up to $\sim 2$ $\mathrm{g} / \mathrm{kg})$.

Significant line-related differences were also observed in terms of ETH preference during the acquisition phase. Thus, both lines preferred ETH over water at low concentrations (i.e., 2\% and 3\%), and RHA rats persisted in their preference for ETH solutions over water with ETH concentrations up to 7\%. With concentrations $\geq 8 \%$, however, no preference for ETH or water was observed in RHA rats. Conversely, ETH preference markedly decreased with escalating concentrations in RLA rats, so that a significant preference for water over ETH was observed with ETH concentrations $\geq 5 \%$. Notably, the decrease in ETH preference with escalating concentrations observed in RLA rats has also been reported in many different outbred and inbred nonselected lines/ strains of ETH non-preferring rats ([40] and references therein) .

ETH intake and preference were larger in RHA vs. RLA rats also throughout the maintenance phase; thus in RHA rats ETH intake remained stable at $\sim 3.5$ to $4 \mathrm{~g} / \mathrm{kg}$ on days 1 to 6 and 9 to 10 , with a small decrease on days 7 and 8 , whereas in RLA rats it was significantly lower $(\sim 1.5 \mathrm{~g} / \mathrm{kg})$. RHA rats did not show preference for ETH or water on days 1 to 6 of the maintenance phase but on days 7 to 10 preferred water over ETH; in contrast, RLA rats preferred water over ETH across the maintenance phase. Collectively, the results obtained using outbred RHA and RLA rats from the colony established in Cagliari are consistent with previous studies in outbred rats from the Swiss sublines (i.e., RHA/Verh and RLA/Verh) [12] [41] as well as in the inbred Roman strains [10] [11], suggesting that the behavioral traits related to ETH preference that distinguish the Roman lines/strains were not modified by changes in the breeding procedure (i.e., outbreeding vs inbreeding).

Upon completion of the maintenance phase rats were shifted to a restricted access schedule for 4 consecutive days in order to ensure consumption of sufficient amounts of water or ETH during the subsequent brain microdialysis experiments. Animals were presented with 2\% ETH solutions during the brain dialysis assays because at that concentration ETH intake was similar in both lines during the acquisition phase. Surprisingly, however, RHA rats drank more than twice the amount of $2 \%$ ETH solution consumed by RLA rats. Furthermore, DA output in the AcbSh increased significantly in RHA rats presented with ETH but not with water, whereas no significant changes in accumbal DA output were observed in RLA rats exposed to either water or ETH.

Although the reason for the greater voluntary consumption of $2 \%$ ETH of RHA vs RLA rats $(0.65 \mathrm{~g} / \mathrm{kg}$ and $0.29 \mathrm{~g} / \mathrm{kg}$, respectively) remains unclear, several mechanisms may be involved in this line-related difference. In this context, ETH deprivation may be a contributing factor; thus, previous reports have shown a pronounced decrease in basal extracellular DA concentrations during the initial phase of withdrawal upon chronic ETH exposure [42] [43]. Those studies were performed within 6 - $12 \mathrm{~h}$ after the cessation of ETH administration, suggesting that deficits in accumbal DA efflux may contribute to the dysphoric symptoms of withdrawal and, thereby, induce ETH-seeking behavior in rats with a history of chronic exposure to ETH [43]. On the other hand, repeated exposure to various addictive substances, including ETH, results in an enhancement of their behavioral effects. This phenomenon, referred to as behavioral sensitization, is manifested in rodents as an increase in drugevoked locomotion after repeated drug administration. Behavioral sensitization is proposed to result from some of the same neuroadaptations that are triggered by repeated drug exposure and that lead to the development of compulsive drug use [28] [44]. Among these neuroadaptations, the plastic modifications of the mesolimbic dopaminergic system induced by chronic drug exposure have received considerable attention and have been ob- 
served upon repeated administration of cocaine, morphine [28] [44], and ETH [45]. It has been proposed that these plastic changes, such as the enhanced accumbal DA efflux after repeated drug exposure, play a pivotal role in the maintenance and reinstatement of compulsive drug-seeking behavior [46].

Notably, several relevant behavioral and neurochemical differences between the Roman lines have been identified along the selective breeding process. Thus, compared with their RLA counterparts, RHA rats display a more robust sensation/novelty seeking profile, as well as higher baseline levels of impulsivity, and a marked preference for and intake of natural and drug rewards [10] [13] [15] [16] [47] [48]. The phenotypic traits that distinguish these lines are at least partly determined by differences in the functional properties of their central dopaminergic pathways: 1) the acute administration of amphetamine, cocaine, and morphine causes a larger increment in motor activity and in DA output in the AcbSh than in the AcbC of RHA but not RLA rats [29]; 2) the repeated administration of psychostimulants and morphine induces behavioral sensitization only in RHA rats [49]-[51]; 3) in sensitized RHA rats, a subsequent challenge with these drugs elicits a more robust increment in DA output in the AcbC, associated with an attenuated dopaminergic response in the AcbSh, whereas these plastic changes are not observed in sensitization-resistant RLA rats [28] [38]. Collectively, these findings indicate that, compared with their RLA counterparts, RHA rats are more responsive to the acute effects of morphine and psychostimulants and more susceptible to develop behavioral and mesolimbic DA sensitization upon repeated exposure to these substances. The above findings, together with the present results support the view that chronic ETH exposure may also have induced behavioral and neurochemical sensitization in RHA but not RLA rats.

Conversely, the selective increment in DA output in the AcbSh of RHA rats may be simply due to the larger amount of ETH consumed by this line as compared with RLA rats. To test this possibility, we performed brain dialysis experiments in naïve Roman rats that were injected i.p. with ETH at the dose of $0.25 \mathrm{~g} / \mathrm{kg}$, which is very similar to the amount of ETH voluntarily consumed p.o. by RLA rats in the previous brain dialysis assays. The result of this experiment was clear cut: the accumbal DA output increased only in RHA rats, further supporting the notion that the mesolimbic dopaminergic projections of RHA rats are more responsive to ETH than those of their RLA counterparts.

Clinical researchers define the sensation-seeking profile as a neurobiologically based tendency to seek novel, complex, intense sensations and a proclivity to take physical, social, legal, and financial risks in order to achieve such experiences [52]. The equivalent construct of sensation-seeking in preclinical research is novelty-seeking, a term used to describe high levels of exploratory activity in response to unfamiliar environments [53]. Rodents that display robust novelty-seeking behaviour also show high responsivity to the reinforcing effects of addictive substances, including ETH, and learn to self-administer such substances very rapidly [54]-[56]. Selectively bred rodent lines and strains exhibiting different behaviours upon exposure to a novel environment and differing in the basal levels of impulsivity, like the Roman lines/strains [10] [13] [15] [16] [47] [57] and other rodent lines [54] [58] may therefore represent valid experimental models to explore the neural underpinnings of noveltyseeking traits and their relationships with the vulnerability to drug addiction.

In summary, the Roman lines differ markedly in a number of traits related to emotionality, sensation seeking, impulsivity, and susceptibility to addiction in humans. Specifically, previous studies have demonstrated that compared with their RLA counterparts, RHA rats exhibit more robust novelty-seeking traits [57] and increased propensity to self-administer addictive drugs [30]. The results reported herein show that, relative to RLA rats, RHA rats also show greater voluntary ETH intake and preference (in keeping with previous studies in the outbred Roman Swiss sublines and in the inbred Roman strains), and a mesolimbic dopaminergic system that is more responsive in terms of accumbal DA efflux assessed by means of brain microdialysis, to the stimulatory effect of ETH, either consumed voluntarily or injected i.p. Beyond the involvement of the mesolimbic dopaminergic system, the neural circuits responsible for these different traits related to impulsivity, novelty-seeking behavior and substance abuse liability are not completely understood, although previous studies have found lineand strain-dependent differences involving noradrenergic, GABAergic and serotonergic neurotransmission [15] [59] [60]. Therefore, the characterization of this genetic animal model for increased vulnerability to drug abuse represents an important step in defining the neural substrates of this disorder and in identifying molecular targets for its treatment.

\section{Acknowledgements}

This work was partially supported by grants from the Italian Ministry of the University and Research (MIUR) to 
OG and MGC, and from ARS (Autonomous Region of Sardinia) (L.R. 7/2007, "Promotion of Scientific Research and Technological Innovation in Sardinia”, European Social Fund, 2007-2013, Project code no. CRP59842) to OG.

\section{References}

[1] Li, T.K. and Lumeng, L. (1984) Alcohol Preference and Voluntary Alcohol Intakes of Inbred Rat Strains and the National Institutes of Health Heterogeneous Stock of Rats. Alcoholism: Clinical and Experimental Research, 8, 485-486. http://dx.doi.org/10.1111/j.1530-0277.1984.tb05708.x

[2] Bisaga, A. and Kostowski, W. (1993) Individual Behavioral Differences and Ethanol Consumption in Wistar Rats. Physiology \& Behavior, 54, 1125-1131. http://dx.doi.org/10.1016/0031-9384(93)90336-E

[3] Li, T.K., Lumeng, L. and Doolittle, D.P. (1993) Selective Breeding for Alcohol Preference and Associated Responses. Behavior Genetics, 23, 163-170. http://dx.doi.org/10.1007/BF01067421

[4] Sinclair, J.D., Lê, A.D. and Kiianmaa, K. (1989) The AA and ANA Rat Lines, Selected for Differences in Voluntary Alcohol Consumption. Experientia, 45, 798-805. http://dx.doi.org/10.1007/BF01954055

[5] Colombo, G., Agabio, R., Lobina, C., Reali, R., Zocchi, A., Fadda, F. and Gessa, G.L. (1995) Sardinian Alcohol-Preferring Rats: A Genetic Animal Model of Anxiety. Physiology \& Behavior, 57, 1181-1185. http://dx.doi.org/10.1016/0031-9384(94)00382-F

[6] Amit, Z. and Smith, B.R. (1992) Differential Ethanol Intake in Tryon Maze-Bright and Tryon Maze-Dull Rats: Implications for the Validity of the Animal Model of Selectively Bred Rats for High Ethanol Consumption. Psychopharmacology (Berl), 108, 136-140. http://dx.doi.org/10.1007/BF02245298

[7] Satinder, K.P. and Wooldridge, G.E. (1986) Emotional Reactivity and Alcohol Preference among Genetic Crosses of the Maudsley and Roman Rats. Pharmacology Biochemistry and Behavior, 24, 879-881. http://dx.doi.org/10.1016/0091-3057(86)90430-2

[8] Broadhurst, P.I. and Bignami, G. (1964) Correlative Effects of Psychogenetic Selection: A Study of the Roman Highand Low-Avoidance Strains of Rats. Behaviour Research and Therapy, 2, 273-280. http://dx.doi.org/10.1016/0005-7967(64)90033-6

[9] Driscoll, P. and Bättig, K. (1982) Behavioral, Emotional and Neurochemical Profiles of Rats Selected for Extreme Differences in Active, Two-Way Avoidance Performance. In: Lieblich, I., Ed., Genetics of the Brain, Elsevier, Amsterdam, 95-123.

[10] Fernández-Teruel, A., Driscoll, P., Gil, L., Aguilar, R., Tobeña, A. and Escorihuela, R.M. (2002a) Enduring Effects of Environmental Enrichment on Novelty Seeking, Saccharin and Ethanol Intake in Two Rat Lines (RHA/Verh and RLA/Verh) Differing in Incentive-Seeking Behavior. Pharmacology Biochemistry and Behavior, 73, 225-231. http://dx.doi.org/10.1016/S0091-3057(02)00784-0

[11] Manzo, L., Gómez, M.J., Callejas-Aguilera, J.E., Fernández-Teruel, A., Papini, M.R. and Torres, C. (2012) Oral Ethanol Self-Administration in Inbred Roman High- and Low-Avoidance Rats: Gradual versus Abrupt Ethanol Presentation. Physiology \& Behavior, 108, 1-5. http://dx.doi.org/10.1016/j.physbeh.2012.07.002

[12] Razafimanalina, R., Mormède, P. and Velley, L. (1996) Gustatory Preference-Aversion Profiles for Saccharin, Quinine and Alcohol in Roman High- and Low-Avoidance Lines. Behavioural Pharmacology, 7, 78-84. http://dx.doi.org/10.1097/00008877-199601000-00008

[13] Escorihuela, R.M., Fernández-Teruel, A., Gil, L., Aguilar, R., Tobeña, A. and Driscoll, P. (1999) Inbred Roman Highand Low-Avoidance Rats: Differences in Anxiety, Novelty-Seeking, and Shuttlebox Behaviors. Physiology \& Behavior, 67, 19-26. http://dx.doi.org/10.1016/S0031-9384(99)00064-5

[14] Giorgi, O., Lecca, D., Piras, G., Driscoll, P. and Corda, M.G. (2003a) Dissociation between Mesocortical Dopamine Release and Fear-Related Behaviors in Two Psychogenetically Selected Lines of Rats That Differ in Coping Strategies to Aversive Conditions. European Journal of Neuroscience, 17, 2716-2726. http://dx.doi.org/10.1046/j.1460-9568.2003.02689.x

[15] Moreno, M., Cardona, D., Gómez, M.J., Sánchez-Santed, F., Tobeña, A., Fernández-Teruel, A., Campa, L., Suñol, C., Escarabajal, M.D., Torres, C. and Flores, P. (2010) Impulsivity Characterization in the Roman High- and LowAvoidance Rat Strains: Behavioral and Neurochemical Differences. Neuropsychopharmacology, 35, 1198-1208. http://dx.doi.org/10.1038/npp.2009.224

[16] Siegel, J. (1997) Augmenting and Reducing of Visual Evoked Potentials in High- and Low-Sensation Seeking Humans, Cats, and Rats. Behavior Genetics, 27, 557-563. http://dx.doi.org/10.1023/A:1021409132320

[17] Steimer, T. and Driscoll, P. (2003) Divergent Stress Responses and Coping Styles in Psychogenetically Selected Roman High-(RHA) and Low-(RLA) Avoidance Rats: Behavioural, Neuroendocrine and Developmental Aspects. Stress, 6, 87-100. http://dx.doi.org/10.1080/1025389031000111320 
[18] Steimer, T. and Driscoll, P. (2005) Inter-Individual vs Line/Strain Differences in Psychogenetically Selected Roman High-(RHA) and Low-(RLA) Avoidance Rats: Neuroendocrine and Behavioural Aspects. Neuroscience \& Biobehavioral Reviews, 29, 99-112. http://dx.doi.org/10.1016/j.neubiorev.2004.07.002

[19] Boersma, G.J., Benthem, L., van Dijk, G. and Scheurink, A.J. (2011) Individual Variation in the (Patho)Physiology of Energy Balance. Physiology \& Behavior, 103, 89-97. http://dx.doi.org/10.1016/j.physbeh.2010.12.026

[20] Fernández-Teruel, A., Escorihuela, R.M., Gray, J.A., Aguilar, R., Gil, L., Giménez-Llort, L., Tobeña, A., Bhomra, A., Nicod, A., Mott, R., Driscoll, P., Dawson, G.R. and Flint, J. (2002b) A Quantitative Trait Locus Influencing Anxiety in the Laboratory Rat. Genome Research, 12, 618-626. http://dx.doi.org/10.1101/gr.203402

[21] Ferré, P., Fernández-Teruel, A., Escorihuela, R.M., Driscoll, P., Corda, M.G., Giorgi, O. and Tobeña, A. (1995) Behavior of the Roman/Verh High- and Low-Avoidance Rat Lines in Anxiety Tests: Relationship with Defecation and SelfGrooming. Physiology \& Behavior, 58, 1209-1213. http://dx.doi.org/10.1016/0031-9384(95)02068-3

[22] Gentsch, C., Lichtsteiner, M. and Feer, H. (1991) Genetic and Environmental Influences on Reactive and Spontaneous Locomotor Activities in Rats. Experientia, 47, 998-1008. http://dx.doi.org/10.1007/BF01923335

[23] López-Aumatell, R., Vicens-Costa, E., Guitart-Masip, M., Martínez-Membrives, E., Valdar, W., Johannesson, M., Cañete, T., Blázquez, G., Driscoll, P., Flint, J., Tobeña, A. and Fernández-Teruel, A. (2009) Unlearned Anxiety Predicts Learned Fear: A Comparison among Heterogeneous Rats and the Roman Rat Strains. Behavioural Brain Research, 202, 92-101. http://dx.doi.org/10.1016/j.bbr.2009.03.024

[24] Piras, G., Piludu, M.A., Giorgi, O. and Corda, M.G. (2014) Effects of Chronic Antidepressant Treatments in a Putative Genetic Model of Vulnerability (Roman Low-Avoidance Rats) and Resistance (Roman High-Avoidance Rats) to Stress-Induced Depression. Psychopharmacology, 231, 43-53. http://dx.doi.org/10.1007/s00213-013-3205-7

[25] Carrasco, J., Márquez, C., Nadal, R., Tobeña, A., Fernández-Teruel, A. and Armario, A. (2008) Characterization of Central and Peripheral Components of the Hypothalamus-Pituitary-Adrenal Axis in the Inbred Roman Rat Strains. Psychoneuroendocrinology, 33,437-445. http://dx.doi.org/10.1016/j.psyneuen.2008.01.001

[26] Gentsch, C., Lichtsteiner, M., Driscoll, P. and Feer, H. (1982) Differential Hormonal and Physiological Responses to Stress in Roman High- and Low-Avoidance Rats. Physiology \& Behavior, 28, 259-263. http://dx.doi.org/10.1016/0031-9384(82)90072-5

[27] Steimer, T., Python, A., Schulz, P.E. and Aubry, J.M. (2007) Plasma Corticosterone, Dexamethasone (DEX) Suppression and DEX/CRH Tests in a Rat Model of Genetic Vulnerability to Depression. Psychoneuroendocrinology, 32, 575579. http://dx.doi.org/10.1016/j.psyneuen.2007.03.012

[28] Giorgi, O., Piras, G. and Corda, M.G. (2007) The Psychogenetically Selected Roman High- and Low-Avoidance Rat Lines: A Model to Study the Individual Vulnerability to Drug Addiction. Neuroscience \& Biobehavioral Reviews, 31, 148-163. http://dx.doi.org/10.1016/j.neubiorev.2006.07.008

[29] Lecca, D., Piras, G., Driscoll, P., Giorgi, O. and Corda, M.G. (2004) A Differential Activation of Dopamine Output in the Shell and Core of the Nucleus Accumbens Is Associated with the Motor Responses to Addictive Drugs: A Brain Dialysis Study in Roman High- and Low-Avoidance Rats. Neuropharmacology, 46, 688-699. http://dx.doi.org/10.1016/j.neuropharm.2003.11.011

[30] Fattore, L., Piras, G., Corda, M.G. and Giorgi, O. (2009) The Roman High- and Low-Avoidance Rat Lines Differ in the Acquisition, Maintenance, Extinction, and Reinstatement of Intravenous Cocaine Self-Administration. Neuropsychopharmacology, 34, 1091-1101. http://dx.doi.org/10.1038/npp.2008.43

[31] Agabio, R., Cortis, G., Fadda, F., Gessa, G.L., Lobina, C., Reali, R. and Colombo, G. (1996) Circadian Drinking Pattern of Sardinian Alcohol-Preferring Rats. Alcohol and Alcoholism, 31, 385-388. http://dx.doi.org/10.1093/oxfordjournals.alcalc.a008166

[32] Colombo, G., Lobina, C., Carai, M.A. and Gessa, G.L. (2006) REVIEW: Phenotypic Characterization of Genetically Selected Sardinian Alcohol-Preferring (sP) and -Non-Preferring (sNP) Rats. Addiction Biology, 11, 324-338. http://dx.doi.org/10.1111/j.1369-1600.2006.00031.x

[33] Imperato, A. and Di Chiara, G. (1986) Preferential Stimulation of Dopamine Release in the Nucleus Accumbens of Freely Moving Rats by Ethanol. Journal of Pharmacology and Experimental Therapeutics, 239, 219-228.

[34] Yoshimoto, K., McBride, W.J., Lumeng, L. and Li, T.K. (1992) Alcohol Stimulates the Release of Dopamine and Serotonin in the Nucleus Accumbens. Alcohol, 9, 17-22. http://dx.doi.org/10.1016/0741-8329(92)90004-T

[35] Yim, H.J., Schallert, T., Randall, P.K. and Gonzales, R.A. (1998) Comparison of Local and Systemic Ethanol Effects on Extracellular Dopamine Concentration in Rat Nucleus Accumbens by Microdialysis. Alcoholism: Clinical \& Experimental Research, 22, 367-374. http://dx.doi.org/10.1111/j.1530-0277.1998.tb03662.x

[36] Pontieri, F.E., Tanda, G. and Di Chiara, G (1995) Intravenous Cocaine, Morphine, and Amphetamine Preferentially Increase Extracellular Dopamine in the "Shell" as Compared with the "Core" of the Rat Nucleus Accumbens. Proceedings of the National Academy of Sciences of the United Statesd of America, 92, 12304-12308. http://dx.doi.org/10.1073/pnas.92.26.12304 
[37] Bustamante, D., Quintanilla, M.E., Tampier, L., Gonzalez-Lira, V., Israel, Y. and Herrera-Marschitz, M. (2008) Ethanol Induces Stronger Dopamine Release in Nucleus Accumbens (Shell) of Alcohol-Preferring (Bibulous) than in Alcohol-Avoiding (Abstainer) Rats. European Journal of Pharmacology, 591, 153-158. http://dx.doi.org/10.1016/j.ejphar.2008.06.069

[38] Giorgi, O., Piras, G., Lecca, D. and Corda, M.G. (2005) Differential Activation of Dopamine Release in the Nucleus Accumbens Core and Shell after Acute or Repeated Amphetamine Injections: A Comparative Study in the Roman High- and Low-Avoidance Rat Lines. Neuroscience, 135, 987-998.

http://dx.doi.org/10.1016/j.neuroscience.2005.06.075

[39] Paxinos, G. and Watson, C. (1998) The Rat Brain in Stereotaxic Coordinates. Academic Press, Sydney.

[40] Overstreet, D.H., Halikas, J.A., Seredenin, S.B., Kampov-Polevoy, A.B., Viglinskaya, I.V., Kashevskaya, O., Badishtov, B.A., Knapp, D.J., Mormede, P., Kiianmaa, K., Li, T.K. and Rezvani, A.H. (1997) Behavioral Similarities and Differences among Alcohol-Preferring and -Nonpreferring Rats: Confirmation by Factor Analysis and Extension to Additional Groups. Alcoholism: Clinical and Experimental Research, 21, 840-848.

[41] Corda, M.G., Lecca, D., Piras, G., Viola, H., Medina, J.H. and Giorgi, O. (2001) Voluntary Ethanol Intake Activates Meso-Accumbal Dopaminergic Transmission in Roman High-Avoidance, but Not Roman Low-Avoidance Rats. Journal of Neurochemistry, 78, 80.

[42] Rossetti, Z.L., Melis, F., Carboni, S., Diana, M. and Gessa, G.L. (1992) Alcohol Withdrawal in Rats Is Associated with a Marked Fall in Extraneuronal Dopamine. Alcoholism: Clinical and Experimental Research, 16, 529-532. http://dx.doi.org/10.1111/j.1530-0277.1992.tb01411.x

[43] Weiss, F., Parsons, L.H., Schulteis, G., Hyytia, P., Lorang, M.T., Bloom, F.E. and Koob, G.F. (1996) Ethanol SelfAdministration Restores Withdrawal-Associated Deficiencies in Accumbal Dopamine and 5-Hydroxytryptamine Release in Dependent Rats. The Journal of Neuroscience, 16, 3474-3485.

[44] Vanderschuren, L.J. and Kalivas, P.W. (2000) Alterations in Dopaminergic and Glutamatergic Transmission in the Induction and Expression of Behavioral Sensitization: A Critical Review of Preclinical Studies. Psychopharmacology, 151, 99-120. http://dx.doi.org/10.1007/s002130000493

[45] Nestby, P., Vanderschuren, L.J., De Vries, T.J., Hogenboom, F., Wardeh, G., Mulder, A.H. and Schoffelmeer, A.N. (1997) Ethanol, Like Psychostimulants and Morphine, Causes Long-Lasting Hyperreactivity of Dopamine and Acetylcholine Neurons of Rat Nucleus Accumbens: Possible Role in Behavioural Sensitization. Psychopharmacology, 133, 69-76. http://dx.doi.org/10.1007/s002130050373

[46] Robinson, T.E. and Berridge, K.C. (2001) Incentive-Sensitization and Addiction. Addiction, 96, 103-114. http://dx.doi.org/10.1046/j.1360-0443.2001.9611038.x

[47] Zeier, H., Baettig, K. and Driscoll, P. (1978) Acquisition of DRL-20 Behavior in Male and Female, Roman High- and Low-Avoidance Rats. Physiology \& Behavior, 20, 791-793. http://dx.doi.org/10.1016/0031-9384(78)90307-4

[48] Giorgi, O., Valentini, V., Piras, G., Di Chiara, G. and Corda, M.G. (1999). Palatable Food Differentially Activates Dopaminergic Function in the CNS of Roman/Verh Lines and Strains of Rats. Society for Neuroscience Meeting Abstract Book, 25, 2152.

[49] Piras, G., Lecca, D., Corda, M.G. and Giorgi, O. (2003) Repeated Morphine Injections Induce Behavioural Sensitization in Roman High- but Not in Roman Low-Avoidance Rats. NeuroReport, 14, 2433-2438. http://dx.doi.org/10.1097/00001756-200312190-00029

[50] Corda, M.G., Piras, G., Lecca, D., Fernández-Teruel, A., Driscoll, P. and Giorgi, O. (2005) The Psychogenetically Selected Roman Rat Lines Differ in the Susceptibility to Develop Amphetamine Sensitization. Behavioural Brain Research, 157,147-156. http://dx.doi.org/10.1016/j.bbr.2004.06.016

[51] Giorgi, O., Piras, G., Lecca, D. and Corda, M.G. (2005) Behavioural Effects of Acute and Repeated Cocaine Treatments: A Comparative Study in Sensitisation-Prone RHA Rats and Their Sensitisation-Resistant RLA Counterparts. Psychopharmacology, 180, 530-538. http://dx.doi.org/10.1007/s00213-005-2177-7

[52] Zuckerman, M. (1994) Behavioral Expressions and Biosocial Bases of Sensation Seeking. Cambridge University Press, New York.

[53] Bardo, M.T., Donohew, R.L. and Harrington, N.G. (1996) Psychobiology of Novelty Seeking and Drug Seeking Behavior. Behavioural Brain Research, 77, 23-43. http://dx.doi.org/10.1016/0166-4328(95)00203-0

[54] Flagel, S.B., Robinson, T.E., Clark, J.J., Clinton, S.M., Watson, S.J., Seeman, P., Phillips, P.E. and Akil, H. (2010) An Animal Model of Genetic Vulnerability to Behavioral Disinhibition and Responsiveness to Reward-Related Cues: Implications for Addiction. Neuropsychopharmacology, 35, 388-400. http://dx.doi.org/10.1038/npp.2009.142

[55] Meyer, A.C., Rahman, S., Charnigo, R.J., Dwoskin, L.P., Crabbe, J.C. and Bardo, M.T. (2010) Genetics of Novelty Seeking, Amphetamine Self-Administration and Reinstatement Using Inbred Rats. Genes, Brain and Behavior, 9, 790798. http://dx.doi.org/10.1111/j.1601-183X.2010.00616.x 
[56] Nadal, R., Armario, A. and Janak, P.H. (2002) Positive Relationship between Activity in a Novel Environment and Operant Ethanol Self-Administration in Rats. Psychopharmacology, 3, 333-338.

[57] Manzo, L., Gómez, M.J., Callejas-Aguilera, J.E., Donaire, R., Sabariego, M., Fernández-Teruel, A., Cañete, A., Blázquez, G., Papini, M.R. and Torres, C. (2014) Relationship between Ethanol Preference and Sensation/Novelty Seeking. Physiology \& Behavior, 133, 53-60. http://dx.doi.org/10.1016/j.physbeh.2014.05.003

[58] Kabbaj, M. (2006) Individual Differences in Vulnerability to Drug Abuse: The High Responders/Low Responders Model. CNS \& Neurological Disorders, Drug Targets, 5, 513-520. http://dx.doi.org/10.2174/187152706778559318

[59] Giorgi, O., Orlandi, M., Escorihuela, R.M., Driscoll, P., Lecca, D. and Corda, M.G. (1994) GABAergic and Dopaminergic Transmission in the Brain of Roman High-Avoidance and Roman Low-Avoidance Rats. Brain Research, 638, 133-138. http://dx.doi.org/10.1016/0006-8993(94)90642-4

[60] Giorgi, O., Piras, G., Lecca, D., Hansson, S., Driscoll, P. and Corda, M.G. (2003) Differential Neurochemical Properties of Central Serotonergic Transmission in Roman High- and Low-Avoidance Rats. Journal of Neurochemistry, 86, 422-431. http://dx.doi.org/10.1046/j.1471-4159.2003.01845.x 
Scientific Research Publishing (SCIRP) is one of the largest Open Access journal publishers. It is currently publishing more than 200 open access, online, peer-reviewed journals covering a wide range of academic disciplines. SCIRP serves the worldwide academic communities and contributes to the progress and application of science with its publication.

Other selected journals from SCIRP are listed as below. Submit your manuscript to us via either submit@scirp.org or Online Submission Portal.
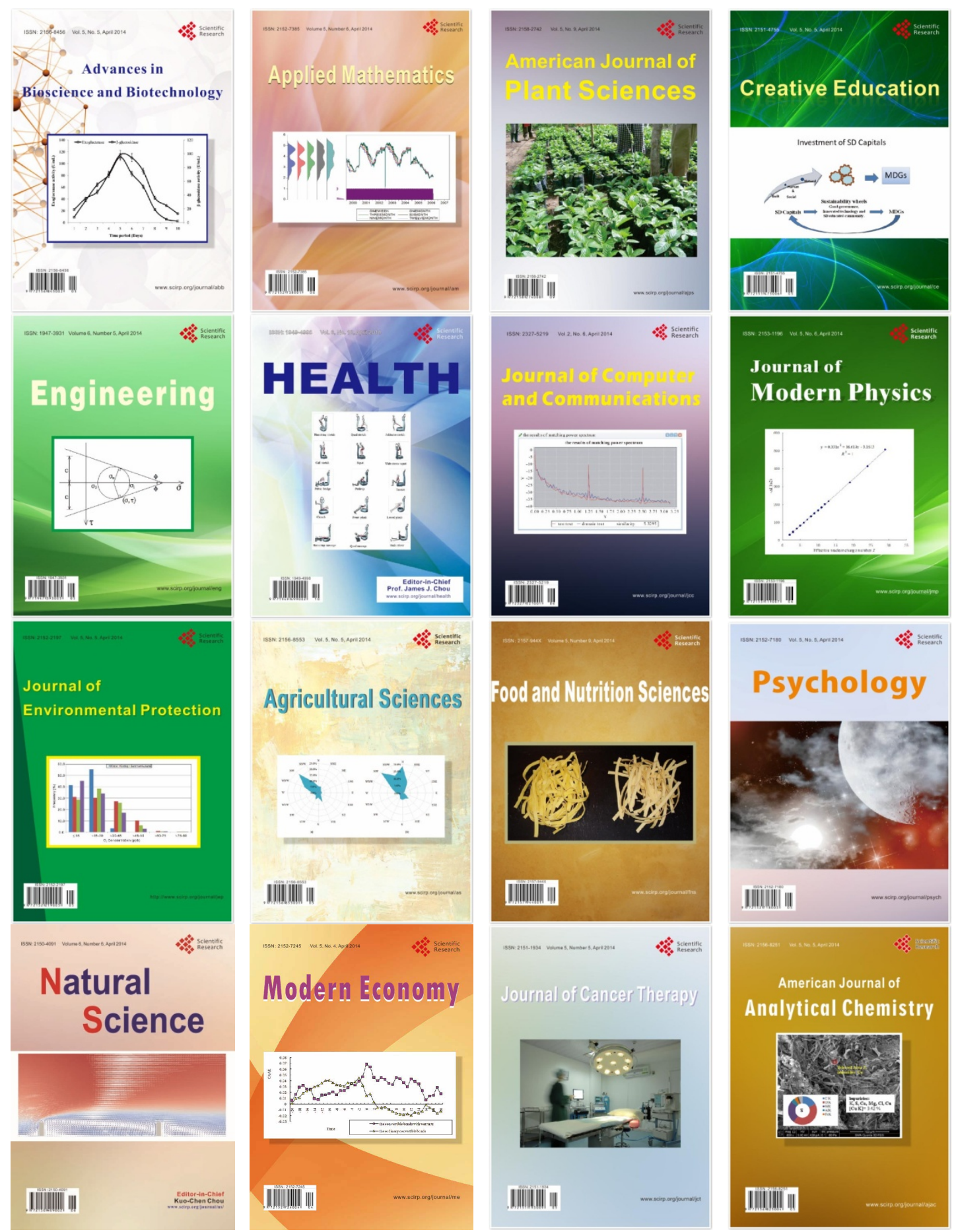